\title{
Source rupture process of the 2011 Fukushima-ken Hamadori earthquake: how did the two subparallel faults rupture?
}

\author{
Miho Tanaka*, Kimiyuki Asano, Tomotaka Iwata and Hisahiko Kubo
}

\begin{abstract}
The 2011 Fukushima-ken Hamadori earthquake ( $M_{w}$ 6.6) occurred about a month after the 2011 Great Tohoku earthquake ( $M_{W}$ 9.0), and it is thought to have been induced by the 2011 Tohoku earthquake. After the 2011 Hamadori earthquake, two subparallel faults (the Itozawa and Yunodake faults) were identified by field surveys. The hypocenter was located nearby the Itozawa fault, and it is probable that the Itozawa fault ruptured before the Yunodake fault rupture. Here, we estimated the source rupture process of the 2011 Hamadori earthquake using a model with two subparallel faults based on strong motion data. The rupture starting point and rupture delay time of the Yunodake fault were determined based on Akaike's Bayesian Information Criterion (ABIC). The results show that the Yunodake fault started to rupture from the northern deep point $4.5 \mathrm{~s}$ after the Itozawa fault started to rupture. The estimated slip distribution in the shallow part is consistent with the surface slip distribution identified by field surveys. Time-dependent Coulomb failure function changes $(\Delta C F F)$ were calculated using the stress change from the Itozawa fault rupture in order to evaluate the effect of the rupture on the Yunodake fault. The $\Delta C F F$ is positive at the rupture starting point of the Yunodake fault $4.5 \mathrm{~s}$ after the Itozawa fault started to rupture; therefore, it is concluded that during the 2011 Hamadori earthquake, the Yunodake fault rupture was triggered by the Itozawa fault rupture.
\end{abstract}

Keywords: 2011 Fukushima-ken Hamadori earthquake; Source rupture process; Kinematic waveform inversion; Time-dependent delta-CFF; Strong ground motion data; Two subparallel faults

\section{Findings Introduction}

The 2011 Fukushima-ken Hamadori earthquake $\left(\mathrm{M}_{\mathrm{W}}\right.$ 6.6) occurred in the southeastern part of Fukushima Prefecture, northeastern Japan (Figure 1a) at 17:16 Japan Standard Time (JST; 08:16 UTC) on 11 April 2011. In northeastern Japan, particularly in northeast Ibaraki and southeast Fukushima prefectures, seismicity associated with swarmlike, shallow normal faulting has increased as a result of the 2011 Great Tohoku earthquake ( $\mathrm{M}_{\mathrm{W}}$ 9.0) (Kato et al. 2013). The 2011 Hamadori earthquake was the largest event in this period. During a field survey, Toda and Tsutsumi (2013) identified two subparallel surface ruptures along the previously mapped Itozawa and Yunodake faults that exhibit a predominantly normal sense of slip. The hypocenter determined by the Japan Meteorological Agency (JMA) has

\footnotetext{
* Correspondence: tanaka.miho.88z@st.kyoto-u.ac.jp

Disaster Prevention Research Institute, Kyoto University, Gokasho, Uji, Kyoto 611-0011, Japan
}

been shown to be close to the Itozawa fault (Figure 1b), which implies that the Itozawa fault ruptured before the Yunodake fault. The difference between strikes of the Itozawa and Yunodake faults is approximately $25^{\circ}$, and they are not conjugated. Interferometric synthetic aperture radar (InSAR)-derived crustal deformation also shows that the Itozawa and Yunodake source faults are not conjugated (e.g., Fukushima et al. 2013; Kobayashi et al. 2013). There are some cases where parallel faults have ruptured during an earthquake (e.g., the 2008 Wenchuan earthquake, China (Tong et al. 2010)). Moreover, there are also some cases where continuous faults have ruptured during an earthquake (e.g., the 1992 Landers earthquake, California (Wald and Heaton 1994) and the 2002 Denali earthquake, Alaska (Asano et al. 2005)). However, no cases have been previously observed where subparallel and unconjugated faults have ruptured during an earthquake, such as the case during the 2011 Fukushima-ken Hamadori earthquake. Therefore, it is important to estimate the

\section{实}



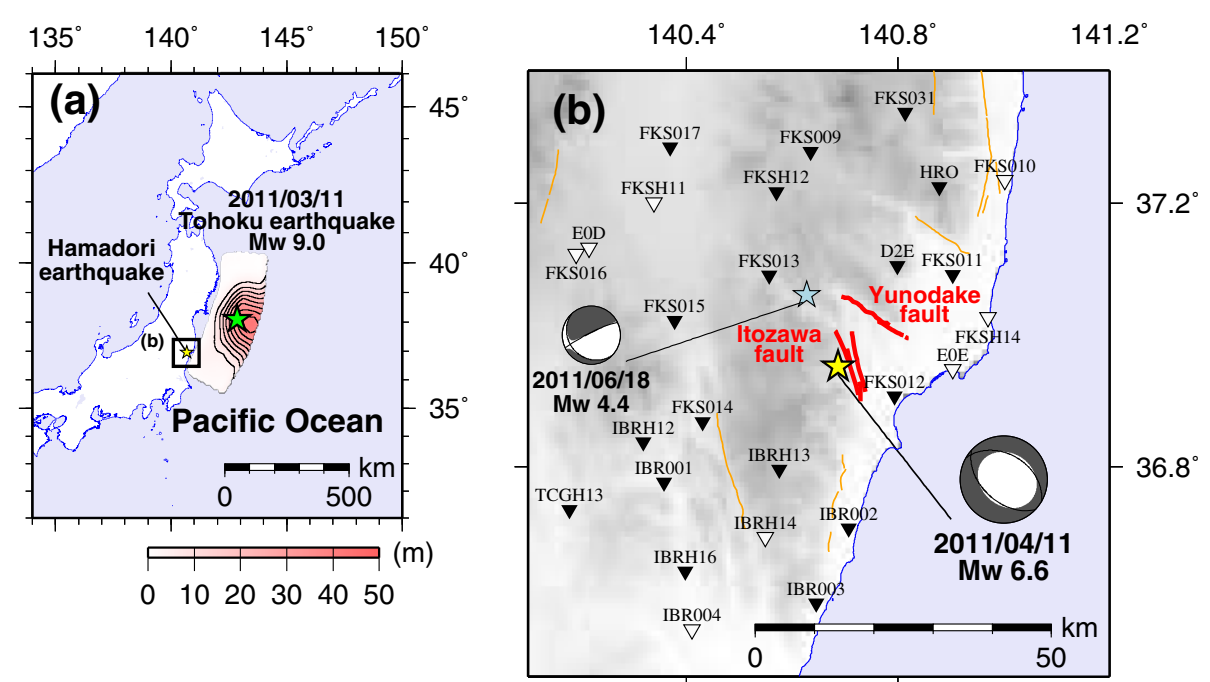

Figure 1 Map showing the location of the study area. (a) The stars indicate the epicenters of the 2011 Tohoku earthquake (green star) and the 2011 Hamadori earthquake (yellow star). The slip distribution of the 2011 Tohoku earthquake by Kubo and Kakehi (2013) is also shown on the map. (b) The stars indicate the epicenters of the 2011 Hamadori earthquake (yellow star) and the aftershock (13:39 JST on 18 June 2011 ) (light blue) with the F-net moment tensor solution and the active faults (AIST 2007) (red and orange lines). The aftershock is used for testing velocity structure models. The white inverted triangles indicate the strong motion stations located within $50 \mathrm{~km}$ of the epicenter. The black inverted triangles are the stations used for the kinematic waveform inversion.

spatiotemporal slip distributions on the source faults with their complicated fault geometry in order to understand the relationship of the two fault ruptures.

In previous studies (Hikima 2012; JMA 2012; Shiba and Noguchi 2012), the source rupture process of this event has been estimated using a two-fault model (the Itozawa and Yunodake faults) based on strong motion data. However, different slip distributions have been identified, particularly in relation to the Yunodake fault. It is considered likely that such differences were caused by variations in the authors' assumptions used for the fault model, particularly in relation to the rupture starting point and rupture delay time of the Yunodake fault.

In this study, in order to obtain slip distributions on the two faults, we objectively determine not only a hyperparameter describing the strength of smoothing constraint but also a set of additional parameters such as rupture starting point, rupture delay time, and firsttime window triggering velocity based on Akaike's Bayesian information criterion (ABIC) (Akaike 1980), whereas previous source inversions determined only hyperparameters (e.g., Ide and Takeo 1997; Sekiguchi et al. 2000). We then calculate the stress field from the estimated moment release history of the Itozawa fault and get temporal changes in the Coulomb failure function (time-dependent $\triangle \mathrm{CFF}$ ) in order to discuss whether the Yunodake fault rupture was triggered by that of the Itozawa fault.

\section{Estimation of the source rupture process using kinematic waveform inversion \\ Data}

The observed ground motions are represented by the convolution of the source, the propagation path, and site effects. In order to use appropriate Green's functions in kinematic waveform inversion analysis, it is necessary to check whether observed waveforms can be reproduced using a given velocity structure model. In this study, we selected strong motion stations based on a comparison between the theoretical and observed waveforms of an aftershock (13:39 JST on 18 June 2011, $\mathrm{M}_{\mathrm{W}} 4.4$ ).

The observed data from 26 strong motion stations of K-NET, KiK-net, F-net, and JMA, which are located within $50 \mathrm{~km}$ of the epicenter of the 2011 Hamadori earthquake (Figure 1b), were used. The original acceleration data from these stations (except F-net stations, which only provide original velocity data) were integrated into velocity; velocity seismograms were then band-pass filtered from 0.1 to $1.0 \mathrm{~Hz}$. Assuming a onedimensional velocity structure model for each station (extracted from the three-dimensional Japan Integrated Velocity Structure Model (Koketsu et al. 2012)), the theoretical waveforms of the aftershock were then calculated using the discrete wave number method (Bouchon 1981) and the reflection and transmission coefficient matrix method (Kennett and Kerry 1979). Theoretical waveforms were then compared with the observed waveforms (Figure 2), and we selected 18 


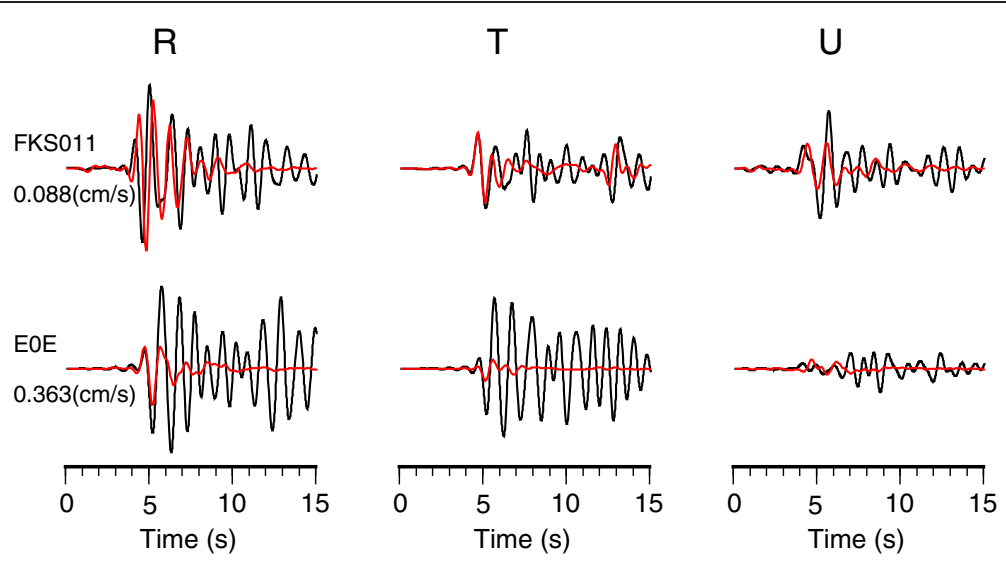

Figure 2 Examples of a comparison between observed waveforms (black lines) and theoretical waveforms (red lines). $R, T$, and $U$ are the radial, transverse, and up-down components, respectively. In the first row, the observed waveforms are well represented; therefore, this station was selected for the kinematic waveform inversion. In the second row, the observed waveforms are not well represented; therefore, this station was not selected.

stations (Figure 1b) where the observed waveforms were found to be well reproduced.

For the kinematic waveform inversion, three components of the velocity seismograms recorded from the 18 selected strong motion stations were used (Figure 1b), and these were band-pass filtered from 0.1 to $1.0 \mathrm{~Hz}$ and resampled at $10 \mathrm{~Hz}$. The dataset comprises $35 \mathrm{~s}$ of the time series from $1.0 \mathrm{~s}$ before the $\mathrm{S}$-wave arrival.

\section{Method}

Green's functions were calculated in the same way as the theoretical waveforms of the aftershock. We assumed a model with two planar faults (using the Itozawa and Yunodake faults) based on the source fault model inferred from the InSAR information analyzed by Fukushima et al. (2013). The setting of the assumed fault model is shown in Table 1 . The Itozawa fault model is divided into 77 subfaults of $2 \times 2 \mathrm{~km}^{2}$ (11 along the strike and 7 along the dip). The Yunodake fault model is also divided into 63 subfaults of $2 \times 2 \mathrm{~km}^{2}$ (9 along the strike and 7 along the dip).

We used the multiple time window linear source inversion method (Hartzell and Heaton 1983) with a spatiotemporal smoothing constraint on slips (Sekiguchi et al. 2000). The rake angle variations were limited within $-90^{\circ} \pm$ $45^{\circ}$ by the non-negative least squares problem (Lawson and
Hanson 1974). The temporal moment release history at each subfault is expressed by a series of six smoothed ramp functions: each has a duration of $1.0 \mathrm{~s}$ and shifts from the preceding one by $0.5 \mathrm{~s}$. We used 63 possible rupture starting points in the Yunodake fault (the center of all the subfaults) and eight cases of the rupture delay time for the Yunodake fault at 3.0, 3.5, 4.0, 4.5, 5.0, 5.5, 6.0, and $6.5 \mathrm{~s}$. In addition, we used six first-time window triggering velocities of $2.04,2.21,2.38,2.55,2.72$, and $2.89 \mathrm{~km} / \mathrm{s}$, which correspond to between $60 \%$ and $85 \%$ of the S-wave velocities in the velocity structure model at the rupture starting point of the Itozawa fault. By using the minimum ABIC condition, we selected the strength of smoothing and the best set of model parameters such as the rupture starting point, the rupture delay time of the Yunodake fault, and the firsttime window triggering velocity. The observational equation and smoothing constraint are combined as

$$
\left[\begin{array}{c}
\mathbf{G} \\
\lambda \mathbf{S}
\end{array}\right] \boldsymbol{m}=\left[\begin{array}{c}
\boldsymbol{d} \\
0
\end{array}\right]
$$

where $\mathbf{G}$ is the $M_{\mathrm{G}} \times N$ matrix of theoretical Green's functions, $\lambda$ is the strength of smoothing, $\mathbf{S}$ is the $M_{\mathrm{S}} \times$ $N$ matrix of the elements of the smoothing constraint equations, $\boldsymbol{m}$ is the model vector, and $\boldsymbol{d}$ is the vector of

Table 1 Setting of the assumed fault model

\begin{tabular}{lllllll}
\hline Fault & $\begin{array}{l}\text { Strike angle } \\
\left({ }^{\circ}\right)\end{array}$ & $\begin{array}{l}\text { Dip angle } \\
\left.\mathbf{(}^{\circ}\right)\end{array}$ & $\begin{array}{l}\text { Size } \\
\left.\mathbf{( k m}^{\mathbf{2}}\right)\end{array}$ & $\begin{array}{l}\text { Latitude } \\
\left({ }^{\circ} \mathbf{N}\right)^{\mathbf{a}}\end{array}$ & $\begin{array}{l}\text { Longitude } \\
\left.\mathbf{(}^{\circ} \mathbf{E}\right)^{\mathbf{a}}\end{array}$ & $\begin{array}{l}\text { Depth } \\
(\mathbf{k m})^{\mathbf{a}}\end{array}$ \\
\hline Itozawa fault & 156 & 73 & $22 \times 14$ & 36.952 & 140.686 & 6.96 \\
Yunodake fault & 130 & 62 & $18 \times 14$ & 37.014 & 140.676 \\
\hline
\end{tabular}

atatitude, longitude, and depth are the values at the rupture starting point. 
the velocity data obtained by integrating the original acceleration data. In this study, ABIC is defined as

$$
\begin{aligned}
\mathrm{ABIC}= & \left(M_{\mathrm{G}}+M_{\mathrm{S}}-N\right) \log \left(\|\boldsymbol{d}-\mathbf{G} \boldsymbol{m}\|^{2}+\lambda^{2}\|\mathbf{S} \boldsymbol{m}\|^{2}\right) \\
& -M_{\mathrm{S}} \log \lambda^{2}+\log \left\|\mathbf{G}^{\mathrm{T}} \mathbf{G}+\lambda^{2} \mathbf{S}^{\mathrm{T}} \mathbf{S}\right\|+C,
\end{aligned}
$$

where $C$ is a constant term.

\section{Results}

The best location of the rupture starting point on the Yunodake fault is indicated by the blue star in Figure 3a, and the rupture delay time is selected as $4.5 \mathrm{~s}$. The best speed of the first-time window triggering is $2.04 \mathrm{~km} / \mathrm{s}$ (60\% of the S-wave velocity at the rupture starting point of the Itozawa fault). In Figure 4, the synthetic waveforms at all stations used in the inversion are compared with the observed waveforms, and these closely reproduced the observed waveforms.

The estimated slip model shows that a large slip area is located in the northwestern shallow part of the Itozawa fault (Figure 3b). The estimated large slip areas on the Yunodake fault are located in the shallow part of the fault plane and in the vicinity of the rupture starting point (Figure 3c). The average amount of slip in the northwestern part of the Itozawa fault that lies within a depth of $5 \mathrm{~km}$ from the earth's surface is approximately $1.3 \mathrm{~m}$, and the average amount of slip of the Yunodake fault that lies within a depth of $5 \mathrm{~km}$ from the earth's surface is approximately $1.0 \mathrm{~m}$. The total seismic moment of this event is estimated to be $1.45 \times 10^{19} \mathrm{~N} \cdot \mathrm{m}$ $\left(\mathrm{M}_{\mathrm{W}}\right.$ 6.7), and the seismic moment released from the Itozawa fault is almost the same as that released from the Yunodake fault.

Toda and Tsutsumi (2013) found a maximum vertical surface slip of $2.1 \mathrm{~m}$ at Shionohira, which is situated northwest of the epicenter along the Itozawa fault. They also found that the shape of the slip distribution of the Itozawa fault was an asymmetric chevron tapering linearly toward the edge. In addition, they found a slip range of 0.1 to $0.9 \mathrm{~m}$ all along the Yunodake fault and a plateau-like slip distribution. Our estimated slip distributions of the two faults in the shallow part are consistent with these observed surface slip distributions, although the observed surface slip along the Yunodake fault $(0.1$ to $0.9 \mathrm{~m})$ is slightly smaller than the estimated average amount of slip $(1.0 \mathrm{~m})$. However, this difference could be explained by the fact that the estimated large slip area is not located in the shallowest part, which would cause the observed surface slip to be slightly smaller than the estimated average amount of slip.

The temporal progression of the slip is shown in Figure 5. The rupture can be seen to propagate mainly to the north-western up-dip direction on the Itozawa fault. On the Yunodake fault, it can be seen to first propagate mainly to the up-dip direction and then to the southeast in the shallow part. In addition, the results show that the Yunodake fault begins to rupture at the time when the Itozawa fault is rupturing.

\section{The effects of the Itozawa fault rupture on the Yunodake fault plane}

\section{Calculation of the time-dependent $\triangle$ CFF}

In a previous study, Hikima (2012) calculated the static $\triangle$ CFF using his final slip model on the Itozawa fault plane and found an area with a positive $\triangle \mathrm{CFF}$ that included his rupture starting point when he assumed the apparent friction coefficient to be 0.8. In our results, which were obtained from the kinematic waveform inversion, the Itozawa fault was found to be in the process of rupturing when the Yunodake fault started to rupture.

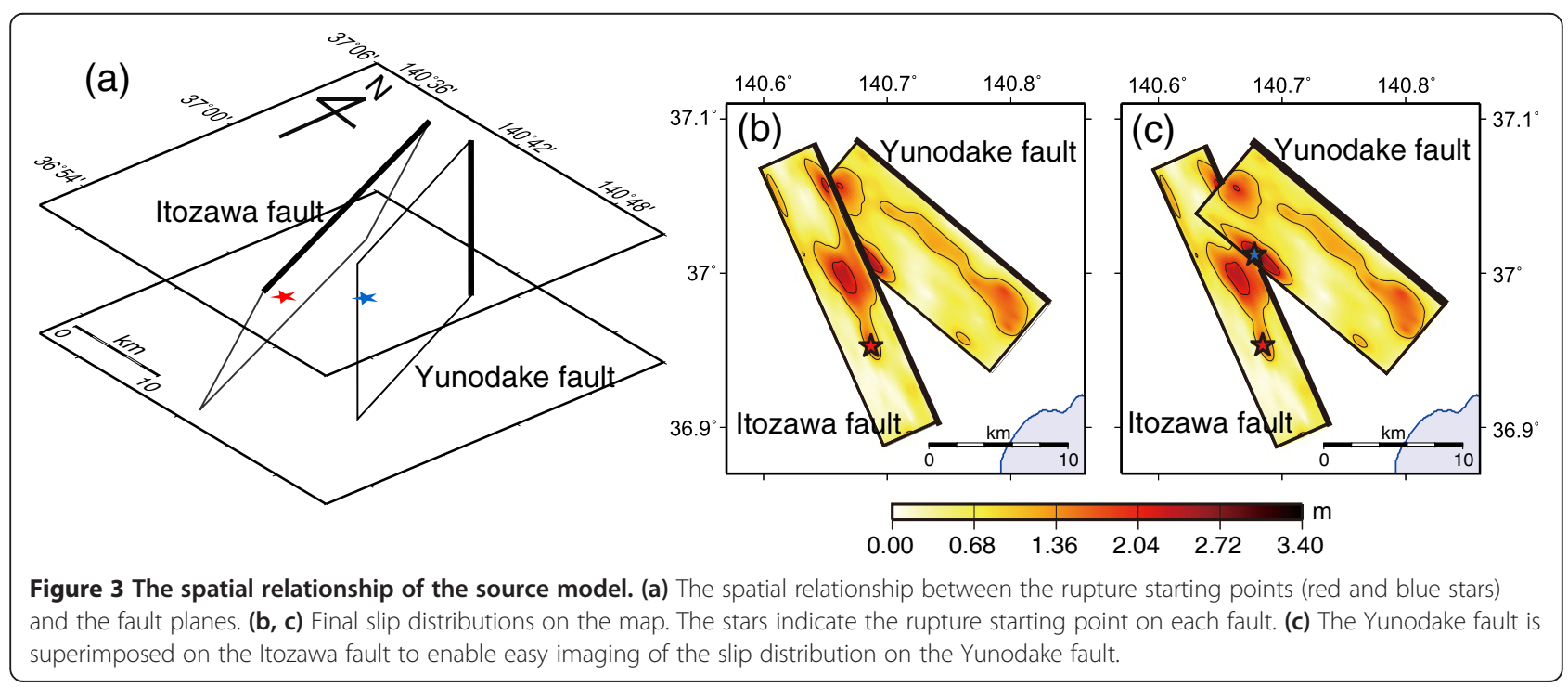




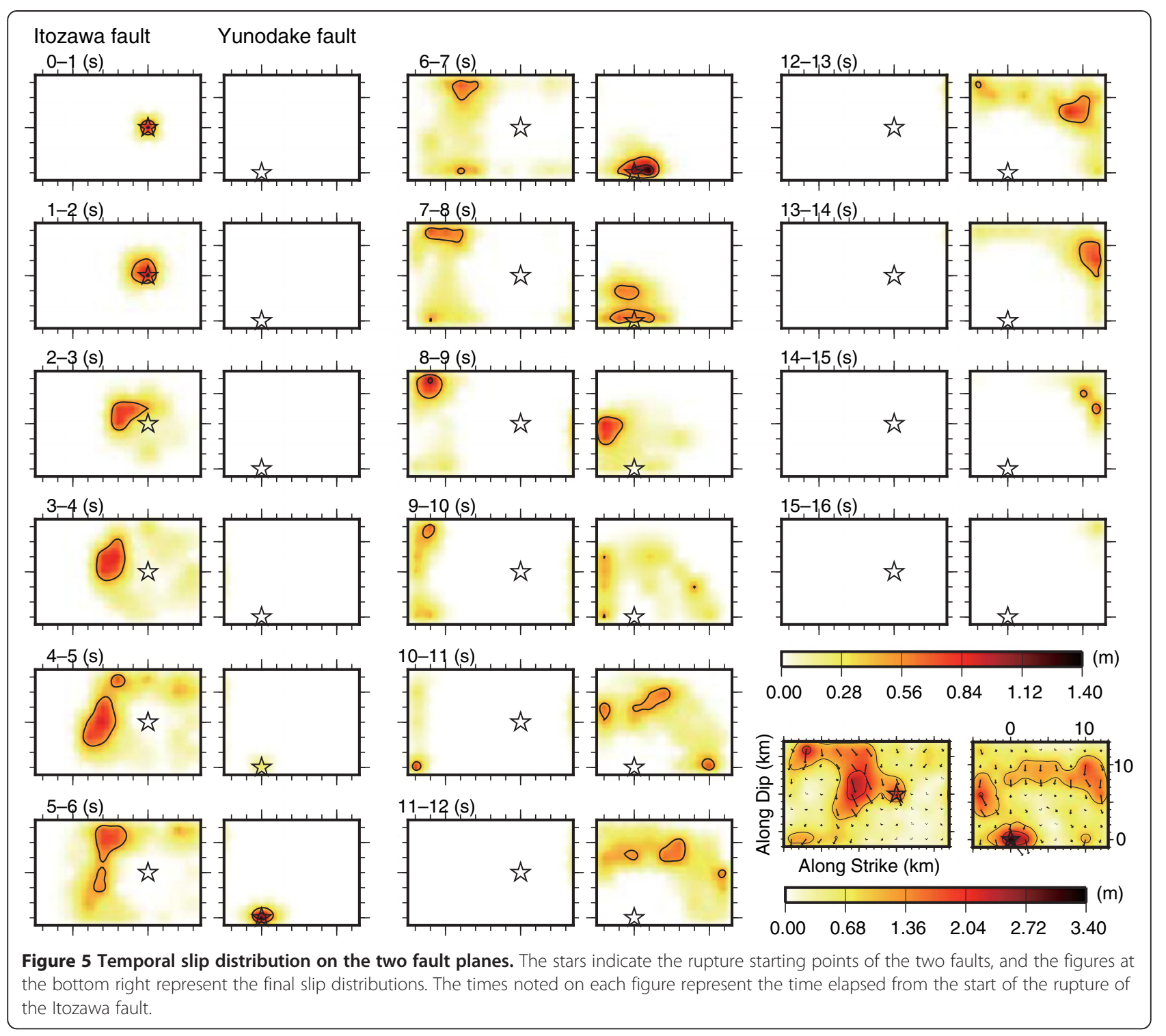

Therefore, we consider it important to calculate the timedependent $\triangle \mathrm{CFF}$ using the obtained moment release history of the Itozawa fault in order to evaluate the effect of the Itozawa fault rupture on the Yunodake fault plane.

\section{Method}

The stress field was calculated by solving the elastodynamic wave equations with the finite difference method (FDM) using discontinuous grids from Ground Motion Simulator (GMS) (Aoi and Fujiwara 1999). The FDM model space was $60 \times 60 \mathrm{~km}^{2}$ in the horizontal direction and $30.1 \mathrm{~km}$ in the depth direction. The underground structure model for the stress field calculation was assumed to be a homogeneous half space, with $V_{\mathrm{P}} V_{\mathrm{S}}$, density, and $Q$ of $5.0 \mathrm{~km} / \mathrm{s}, 2.9 \mathrm{~km} / \mathrm{s}, 2.6 \times 10^{3} \mathrm{~kg} / \mathrm{m}^{3}$, and 680 , respectively. The discontinuous grid system consists of two regions with different grid spacings. The grid spacing of the shallower region is small, whereas the grid spacing of the deeper region is three times coarser (Aoi and Fujiwara 1999). We used discontinuous grids that consisted of a grid spacing of $0.05 \mathrm{~km}$ in the shallower region up to the depth of $18.55 \mathrm{~km}$ (including the Itozawa and Yunodake faults) and of $0.15 \mathrm{~km}$ in the deeper region. The moment release history of the Itozawa fault plane is given by the spatially interpolated model of the obtained slip model using the kinematic waveform inversion with intervals of 2.0 to $0.4 \mathrm{~km}$. The time-dependent $\Delta \mathrm{CFF}$ is calculated according to $\Delta \mathrm{CFF}=\Delta \tau+\mu^{\prime} \Delta \sigma$ (e.g., Toda et al. 2011), where $\tau$ is the shear stress, $\sigma$ is the normal stress on the fault plane, and $\mu^{\prime}$ is the apparent friction coefficient. In this study, two cases of $\mu^{\prime}=0.4$ and 0.8 were tried. For shear stress $\tau$, the positive direction is set to the slip direction of the first-time window at the rupture starting point of the Yunodake fault. 


\section{Results}

For $\mu^{\prime}=0.8$, the time-dependent $\Delta$ CFF has a positive value of approximately $0.8 \mathrm{MPa}$ at the rupture starting point of the Yunodake fault $4.5 \mathrm{~s}$ after the Itozawa fault begins to rupture (Figure 6a,b). Furthermore, for $\mu^{\prime}=$ 0.4 , the time-dependent $\triangle \mathrm{CFF}$ also has a positive value of approximately $0.3 \mathrm{MPa}$ at the rupture starting point of the Yunodake fault, $4.5 \mathrm{~s}$ after the Itozawa fault begins to rupture (Figure 6c,d). Therefore, in consideration of such results, it is concluded that the Itozawa fault rupture triggered the Yunodake fault rupture.

\section{Discussion}

In the previous section, it was demonstrated that the rupture of the Yunodake fault was caused by the dynamic effect of the rupture of the Itozawa fault. However, it is possible that the effects of other earthquakes such as the 2011 Tohoku earthquake could have impacted the Yunodake fault; accordingly, this possibility is also investigated.

Toda et al. (2011) calculated the static $\triangle$ CFF on known major faults and megathrusts using the source model of the 2011 Tohoku earthquake and the $M_{W} 7.9$ aftershock, and the results showed that the static $\triangle \mathrm{CFF}$ on the fault near the Yunodake fault has a positive value of approximately $0.1 \mathrm{MPa}$ when an apparent friction coefficient of 0.4 is adopted. However, the static $\triangle \mathrm{CFF}$ on the Yunodake fault was not calculated in that study. Therefore, in order to discover whether the Itozawa fault rupture triggered the Yunodake fault rupture, we calculated the effect of the static $\triangle C F F$ of the 2011 Tohoku earthquake on the Yunodake fault; the static $\triangle$ CFF was calculated based on Okada (1992) using the final slip distribution of the 2011 Tohoku earthquake (Kubo and Kakehi 2013). The value of the static $\triangle$ CFF at the rupture starting point of the Yunodake fault was found to have a positive value of approximately $0.15 \mathrm{MPa}$, which is considerably smaller than the time-dependent $\triangle \mathrm{CFF}$ of +0.8 $\mathrm{MPa}$ from the rupture of the Itozawa fault. Therefore, we consider this to indicate that the rupture of the Yunodake fault was triggered primarily by the rupture of the Itozawa fault.

\section{Conclusions}

The source rupture process of the 2011 Hamadori earthquake was estimated using fault model parameters such as the rupture starting point and the rupture delay time of the Yunodake fault. The results show that the Yunodake fault began to rupture from the northern deep point $4.5 \mathrm{~s}$ after the Itozawa fault began to rupture. The estimated final slip distributions are consistent with the surface slip distributions found by the field surveys.

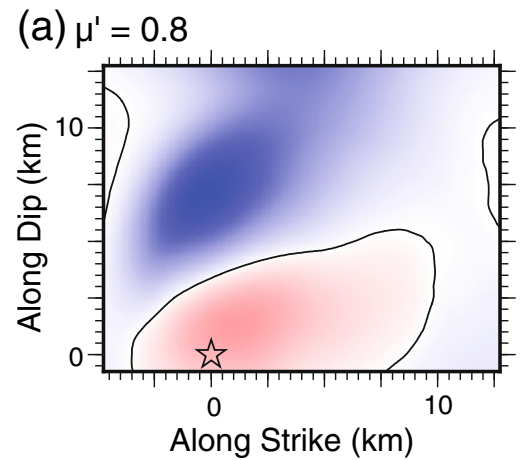

(c) $\mu^{\prime}=0.4$

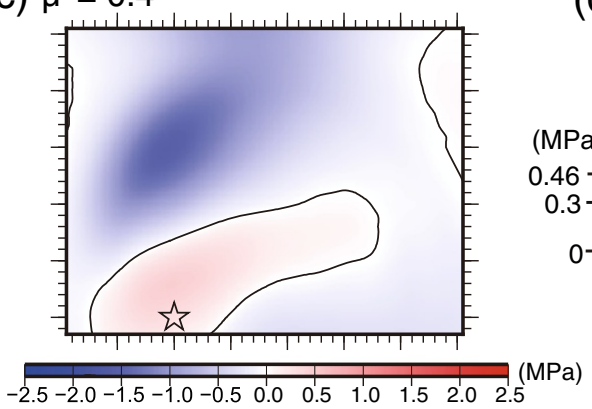

(b)

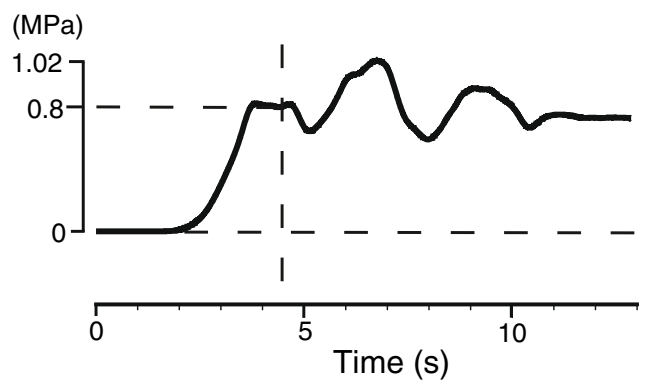

(d)

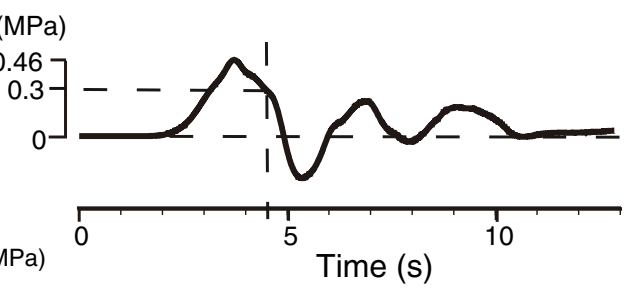

Figure 6 The time-dependent $\Delta$ CFF. (a, c) The distribution of $\Delta$ CFF on the Yunodake fault plane at $4.5 \mathrm{~s}$ after the Itozawa fault begins to rupture. The stars indicate the rupture starting point of the Yunodake fault. (b, $\mathbf{d})$ Time-dependent $\Delta$ CFF at the rupture stating point of the Yunodake fault. ' $0 \mathbf{s}^{\prime}$ is the time at which the Itozawa fault starts to rupture. The top panels $(\mathbf{a}, \mathbf{b})$ are for $\mu^{\prime}=0.8$, and the bottom panels (c, $\mathbf{d}$ ) are for $\mu^{\prime}=0.4$ 
The time-dependent $\triangle \mathrm{CFF}$ was then calculated using the estimated moment release history on the Itozawa fault plane, and it was found to be positive at the rupture starting point of the Yunodake fault, $4.5 \mathrm{~s}$ after the Itozawa fault began to rupture. Furthermore, the obtained time-dependent $\triangle \mathrm{CFF}$ was found to be larger than the static $\triangle$ CFF caused by the 2011 Tohoku earthquake, which implies that the effect of the Itozawa fault rupture on the Yunodake fault plane was larger than that of the 2011 Tohoku earthquake. Therefore, we conclude that during the Hamadori earthquake, the rupture of the Yunodake fault was triggered by the rupture of the Itozawa fault. Considering our results, it may be said that the rupturing of these unconjugated faults was due to the dynamic effect.

\section{Competing interests}

The authors declare that they have no competing interests.

\section{Authors' contributions}

MT analyzed the data, conducted the simulations, and drafted the manuscript. KA and HK participated in the design of study. TI conceived of the study, and participated in the design of study and coordination. All authors read and approved the final manuscript.

\section{Acknowledgements}

We thank two anonymous reviewers and Associate Editor Tomomi Okada for their valuable comments that improved our manuscript. Strong motion data of K-NET, KiK-net, F-net, and Ground Motion Simulator (GMS) were provided by the National Research Institute for Earth Science and Disaster Prevention, Japan. The hypocenter catalog and strong motion data were obtained from the Japan Meteorological Agency. The Generic Mapping Tools software (Wessel and Smith 1998) was used to produce the figures. This study was supported by the Ministry of Education, Culture, Sports, Science and Technology (MEXT) of Japan, under its Earthquake and Volcano Hazards Observation and Research Program.

Received: 4 April 2014 Accepted: 12 August 2014

Published: 26 August 2014

\section{References}

AIST (National Institute of Advanced Industrial Science and Technology) (2007) Active Fault Database of Japan, December 13, 2007 version. AIST, Tsukuba

Akaike H (1980) Likelihood and the Bayes procedure. In: Bernardo JM, DeGroot MH, Lindley DV, Smith AFM (eds) Bayesian Statistics. University Press, Valencia, pp 143-166

Aoi S, Fujiwara H (1999) 3-D finite-difference method using discontinuous grids. Bull Seismol Soc Am 89:918-930

Asano K, Iwata T, Irikura K (2005) Estimation of source rupture process and strong ground motion simulation of the 2001 Denali, Alaska, earthquake. Bull Seismol Soc Am 95:1701-1715

Bouchon M (1981) A simple method to calculate Green's function for elastic layered media. Bull Seismol Soc Am 71:959-971

Fukushima Y, Takada Y, Hashimoto M (2013) Complex ruptures of the 11 April $2011 M_{w} 6.6$ Iwaki earthquake triggered by the 11 March $2011 M_{w} 9.0$ Tohoku earthquake, Japan. Bull Seismol Soc Am 103:1572-1583

Hartzell SH, Heaton T (1983) Inversion of strong ground motion and teleseismic waveform data for the fault rupture history of the 1979 Imperial Valley, California, earthquake. Bull Seismol Soc Am 73:1553-1583

Hikima K (2012) Rupture process of the April 11, 2011 Fukushima Hamadori Earthquake ( $\left.M_{\mathrm{j}} 7.0\right)$ - two fault planes inferred from strong motion and relocated aftershocks, Zisin 2. J Seismol Soc Japan 64:243-256, in Japanese with English abstract

Ide S, Takeo M (1997) Determination of constitutive relations of fault slip based on seismic wave analysis. J Geophys Res 102:27379-27391

JMA (Japan Meteorological Agency) (2012) Report on the 2011 off the Pacific Coast of Tohoku Earthquake, Technical Report of the Japan Meteorological
Agency, No. 133. Japan Meteorological Agency, Tokyo, in Japanese with English abstract

Kato A, Igarashi T, Obara K, Sakai S, Takeda T, Saiga A, lidaka T, Iwasaki T, Hirata N, Goto K, Miyamachi H, Matsushima T, Kubo A, Katao H, Yamanaka Y, Terakawa T, Nakamichi H, Okuda T, Horikawa S, Tsumura N, Umino N, Okada T, Kosuga M, Takahashi H, Yamada T (2013) Imaging the source regions of normal faulting sequences induced by the 2011 M9.0 Tohoku-Oki earthquake. Geophys Res Lett 40:273-278

Kennett BLN, Kerry NJ (1979) Seismic waves in a stratified half space. Geophys J R Astron Soc 57:557-583

Kobayashi T, Tobita M, Koarai M, Okatani T, Suzuki A, Noguchi Y, Yamanaka M, Miyahara B (2013) InSAR-derived crustal deformation and fault models of normal faulting earthquake (Mj 7.0) in the Fukushima-Hamadori area. Earth Planets Space 64:1209-1221

Koketsu K, Miyake H, Suzuki H (2012) Japan Integrated Velocity Structure Model Version 1, paper no. 1773. Paper Presented at the 15th World Conference on Earthquake Engineering, International Association for Earthquake Engineering, Lisbon, 24-28 Sept

Kubo H, Kakehi Y (2013) Source process of the 2011 Tohoku earthquake estimated from the joint inversion of teleseismic body waves and geodetic data including seafloor observation data: source model with enhanced reliability by using objectively determined inversion setting. Bull Seismol Soc Am 103:1195-1220

Lawson CL, Hanson RJ (1974) Solving Least Squares Problems. Prentice-Hall, Old Tappan

Okada Y (1992) Internal deformation due to shear and tensile faults in a half-space. Bull Seismol Soc Am 82:1018-1040

Sekiguchi H, Irikura K, Iwata T (2000) Fault geometry at the rupture termination of the 1995 Hyogo-ken Nanbu earthquake. Bull Seismol Soc Am 90:117-133

Shiba Y, Noguchi S (2012) Statistical characteristics of seismic source parameters controlling broadband strong ground motions - investigation based on source inversion analysis, Rep. No. N11054. Central Research Institute of Electric Power Industry, Tokyo, in Japanese

Toda S, Tsutsumi H (2013) Simultaneous reactivation of two, subparallel, inland normal faults during the $M_{w} 6.611$ April 2011 Iwaki earthquake triggered by the M 9.0 Tohoku-oki, Japan, Earthquake. Bull Seismol Soc Am 103:1584-1602

Toda S, Lin J, Stein RS (2011) Using the 2011 Mw 9.0 off the Pacific coast of Tohoku earthquake to test the Coulomb stress triggering hypothesis and to calculate faults brought closer to failure. Earth Planets Space 63:725-730

Tong X, Sandwell DT, Fialko Y (2010) Coseismic slip model of the 2008 Wenchuan earthquake derived from joint inversion of interferometric synthetic aperture radar, GPS, and field data. J Geophys Res 115, B04314

Wald JD, Heaton TH (1994) Spatial and temporal distribution of slip for the 1992 Landers, California, earthquake. Bull Seismol Soc Am 84:668-691

Wessel P, Smith WHF (1998) New, improved version of generic mapping tools released. EOS Trans Am Geophys Union 79:579

doi:10.1186/1880-5981-66-101

Cite this article as: Tanaka et al:: Source rupture process of the 2011 Fukushima-ken Hamadori earthquake: how did the two subparallel faults rupture? Earth, Planets and Space 2014 66:101.

\section{Submit your manuscript to a SpringerOpen ${ }^{\circ}$ journal and benefit from:}

- Convenient online submission

Rigorous peer review

- Immediate publication on acceptance

- Open access: articles freely available online

- High visibility within the field

- Retaining the copyright to your article

Submit your next manuscript at $>$ springeropen.com 